\title{
Buckling analysis of open-topped steel tanks under external pressure
}

\author{
Jianhua Pan ${ }^{1,2} \cdot$ Shenglin Liang ${ }^{1}$
}

Received: 2 September 2019 / Accepted: 27 February 2020 / Published online: 3 March 2020

(c) Springer Nature Switzerland AG 2020

\begin{abstract}
Oil storage tanks are typically thin-walled structures which are susceptible to buckling under external load. This paper explores the buckling behavior of two in-services $100,000 \mathrm{~m}^{3}$ open-topped tanks under external load by finite element simulation. The finite element analyses are first carried out to explore the stability of in-services tanks under the uniform external pressure and the wind load. And comparison with that three formulae which uses for calculating the critical buckling load of the tank under uniform external pressure. Then carried out the nonlinear buckling analysis by arc-length method, the results show that for in-services tanks, the linear elastic bifurcation analysis also is a good signal for the buckling load. Finally, this paper focus on the influence of wind girders and other reinforcement devices on the buckling behavior of in-services tanks and the strengthening mechanism of the stored liquid to in-service tanks with reinforcement devices. The reinforcement device affects the buckling behavior of the oil-storage tank by strengthening the stiffness of the top of the tank. However, the stored liquid through increasing the stiffness of the bottom of tanks to add the stability of tanks. And the result shows that compared to the oil-storage tank without reinforcement devices. The strengthening effect of the liquid on the tank containing reinforcement devices is more significant.
\end{abstract}

Keywords Buckling $\cdot$ Open-topped $\cdot$ Steel tank $\cdot$ LBA $\cdot$ Strengthening device $\cdot$ In-service

\section{Introduction}

In the twenty-first century, petroleum as an important strategic energy reserve has received great attention from various countries [1-3]. With the increase in oil production, the form of the storage tank has changed from the simple equal-wall tank to the large storage tank with variable wall thickness. Especially in recent decades, as the oil industry of numerous countries expands, the types of oil tanks have changed dramatically. Oil-tanks changes from tens of thousands of cubic meters to more than $100,000 \mathrm{~m}^{3}$ of tanks.

Oil storage tanks are usually vertical cylindrical welded steel tanks, a typical thin-walled structure, which is prone to buckling and other damage under the action of wind load. Looking back on the past decades, the destruction of oil storage tanks in typhoons has been innumerable [4-6]. Therefore, in order to avoid huge economic losses and environmental pollution caused by the destruction of oil storage tanks in typhoons. The buckling failure of oil storage tanks and similar thin-walled cylindrical structures under wind load has been extensively reviewed by scholars in various countries in the past decade [7].

Flores and Godoy [5] studied the buckling behavior of short cylindrical shells under strong wind loads by a numerical method, where the model adopts the tanks that were destroyed during the hurricane. Portela and Godoy $[8,9]$ discussed the buckling problem of tanks with conical or dome roofs caused by wind loads, tested the sensitivity of defects by geometric nonlinear analysis, and studied the influence of floating plate on the buckling behavior of tanks by using the same cylindrical model and wind load.

\footnotetext{
$\triangle$ Jianhua Pan, panjianhua_123@163.com | ${ }^{1}$ Anhui Province Key Lab of Aerospace Structural Parts Forming Technology and Equipment, Institute of Industry and Equipment Technology, Hefei University of Technology, Hefei 230009, China. ${ }^{2}$ National Engineering and Technology Research Center on Pressure Vessel and Piping Safety, Hefei General Machinery Research Institute, Hefei 230031, China.
} 
In recent years, with the development of finite element technology, Zhao et al. [10] through a large number of numerical analyses, illustrated the buckling behavior of the storage tank. Zhao and Lin [11] has compared the buckling behavior of tanks of different sizes and studied the similarities and differences of them under wind load. Maraveas et al. [12] made a comparison of current storage tank standards in Europe and API650, and propose some constructive comments about the current standards. Amir et al. [13] considered the effect of corrosion effect and aging of surface steel cylindrical storage tank under external pressure on its buckling behavior. Uematsu et al. $[14,15]$ based on finite element analysis, studied the wind resistance design problem of wind-resistant structure of open-topped storage tanks and the influence of top/ medium anti-winds device on buckling behavior.

Most of these are based on the tank parameters in the design stage. It focuses on the influence of the imperfection or the reinforcement device on the buckling behavior of empty tanks under the wind load. However, in-service tanks almost have installed different size parameters of reinforcement devices. And before weather disasters such as typhoons or strong winds arrive, the storage state of the tank is often not simply empty or full. Therefore, depending on the numerical simulation method recommended by EN1993-1-6 [16], linear buckling analysis and geometrically nonlinear buckling analysis, this paper explored the buckling behavior of each storage tank under wind load. And study the strengthening mechanism of stored liquid to in-service storage tanks and the influence of reinforcement devices on the buckling behavior of storage tanks.

The main contents are as follows: Sect. 2 expatiates upon the structure prototypes of two tanks. The finite element models used for analyses and the wind pressures on both external and internal walls of tanks. Section 3 presents the linear buckling behavior of the storage tank under wind load. And compared the calculation accuracy of three formulae which use for calculating the critical buckling load of the tank under the uniform external pressure. Section 4 investigated geometrically nonlinear buckling behavior. Section 5 discusses the influence of reinforcement devices on the buckling behavior of tanks and the strengthening mechanism of the stored liquid to the in-service storage tank containing reinforcement devices. Finally, some valuable conclusions are drawn in Sect. 6.

\section{Computational models}

\subsection{Structural prototypes}

The tanks analyzed and compared in this paper are opentopped tanks of $100,000 \mathrm{~m}^{3}$ in service of Sinopec, named
Tank1 and Tank2. Figure 1 shows the relative sizes of different tanks. The walls of those two tanks are similar in thickness and have reinforcement devices of nearly the same size. These two types of tanks reflect the structural parameters of a batch of open-topped tanks in China.

The two tanks have the same aspect ratio $H / D=0.27$, radius-thickness ratio (calculated by minimum diameter thickness and maximum wall thickness) $D / t=2500$ (Tank1), $\mathrm{D} / \mathrm{t}=2461$ (Tank2). Table 1 listed specific wall dimensions. Table 2 listed the dimensions of stiffeners.

\subsection{Finite element model}

In this paper, the commercial finite element software Abaqus is employed to carry out this analysis. In Abaqus, the 8-node, quadrilateral, first-order interpolation, stress/displacement continuum shell element with reduced integration S8R5 chosen to discretize the cylindrical wall. The bottom boundary condition of the tank both fixed and the upper part is free. The material of cylindrical shell assumed to be isotropic elastic with an elastic modulus $E$ of $2.06 \times 10^{5} \mathrm{~N} / \mathrm{mm}^{2}$ and a Poisson's ratio $\mu$ of 0.3 . The finite element model of tanks is shown in Fig. 2.

\subsection{External loads on tanks}

The study of the external pressure of tanks can be divided into two parts: the uniform external pressure and the wind load. The form of uniform external pressure is simple, but the wind load distribution on the tank is various complicated.

The distribution of pressure around vertical cylindrical tanks under wind load has been studied in many literatures. Accordingly, the wind pressure $P$ acting on the structure surfaces can be defined as [17]:

$P=c_{p} q(z)$

where $c_{p}$ is the wind pressure coefficient and $q(z)$ is the velocity pressure of incoming wind which varies with the height.

Because the height of the tank is generally not high, so the change of wind load wind pressure coefficient in the height direction can be ignored. Those studies are only needed to consider the change of the circumferential upperpressure coefficient of the tank. And in the study of the circumferential wind pressure coefficient of the tank more perfected, the distribution of wind loads can use the Fourier series decomposition expression as follows:

$c_{p}(\theta)=\sum_{i=0}^{m} a_{i} \cos (i \theta)$ 
Fig. 1 Section of Tank1 and Tank2 wall

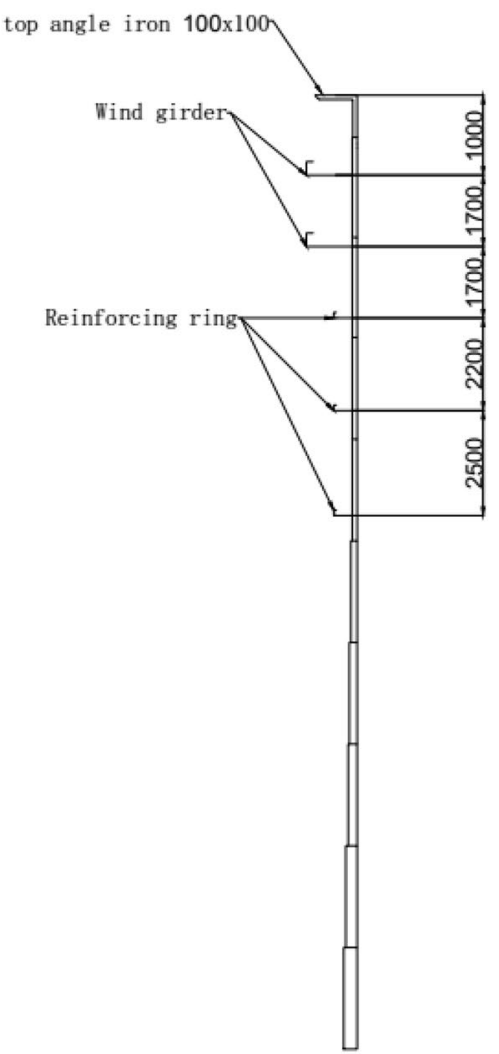

Tank1

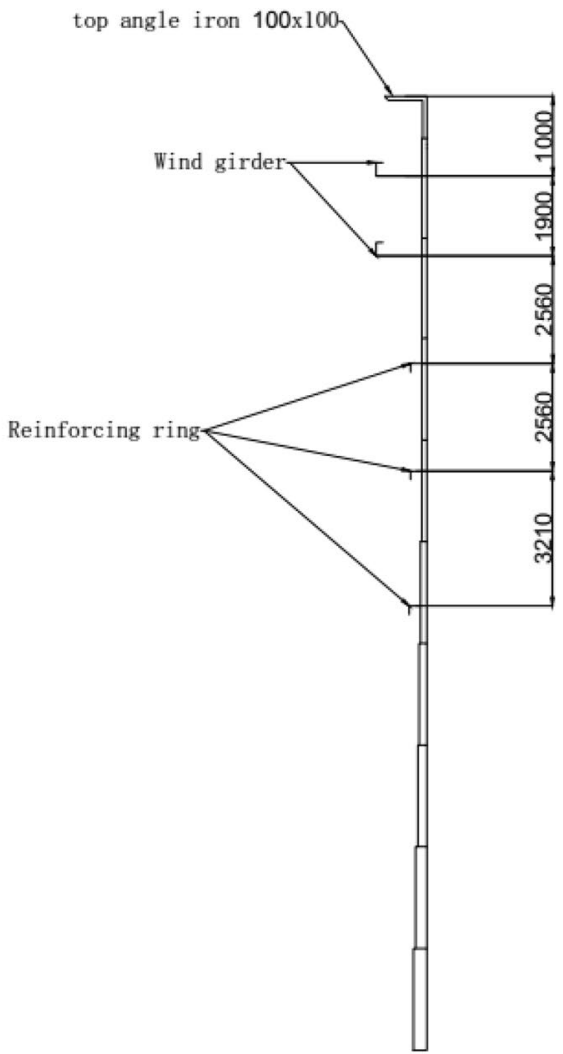

Tank2
Table 1 Tanks specific parameters

\begin{tabular}{lll}
\hline Course $\left(h_{i} \times t_{i}\right)$ & Tank1 $(\mathrm{mm})$ & Tank2 $(\mathrm{mm})$ \\
\hline 1 (bottom) & $2420 \times 32$ & $2420 \times 32.5$ \\
2 & $2420 \times 27$ & $2420 \times 24.5$ \\
3 & $2420 \times 21.5$ & $2420 \times 21.5$ \\
4 & $2420 \times 18.5$ & $2420 \times 18$ \\
5 & $2420 \times 15$ & $2420 \times 15$ \\
6 & $2420 \times 12$ & $2420 \times 12$ \\
7 & $2420 \times 12$ & $2420 \times 12$ \\
8 & $2380 \times 12$ & $2380 \times 12$ \\
9 & $2380 \times 12$ & $2380 \times 12$ \\
10 (Angle) & $100 \times 10$ & $100 \times 10$ \\
\hline
\end{tabular}

where $\theta$ is the longitude measured from the windward, and $a_{i}$ is the Fourier coefficient. Representative Fourier coefficients gained from typical studies and design codes are summarized in Table 3 [18-20].

It can be observed that although the Fourier coefficients matching to each wind pressure coefficient are different, their matching wind load distribution forms are generally the same (Fig. 3). The wind load has a symmetrical distribution of a stationary point, which shows positive pressure in the range of $0^{\circ}-30^{\circ}$ and negative pressure from $30^{\circ}$ to $180^{\circ}$. The maximum positive pressure occurs at the stationary point and then decreases gradually. After converting to negative pressure around
Table 2 The dimensions of stiffeners

\begin{tabular}{llllll}
\hline & Tank1 & & & Tank2 \\
& Web size $(\mathrm{mm})$ & Edge beam size $(\mathrm{mm})$ & & Web size $(\mathrm{mm})$ & Edge beam size $(\mathrm{mm})$ \\
\hline 1st Girder & $1090 \times 12$ & $2 \times 160 \times 14$ & $1150 \times 12$ & $360 \times 96 \times 9$ \\
2nd Girder & $1090 \times 12$ & $2 \times 160 \times 14$ & & $1150 \times 12$ & $360 \times 96 \times 9$ \\
1st Ring & $440 \times 6$ & $160 \times 65 \times 8.5$ & & $270 \times 12$ & $200 \times 12$ \\
2nd Ring & $440 \times 6$ & $160 \times 65 \times 8.5$ & & $270 \times 12$ & $200 \times 12$ \\
3rd Ring & $440 \times 6$ & $160 \times 65 \times 8.5$ & & $270 \times 12$ & $200 \times 12$ \\
\hline
\end{tabular}




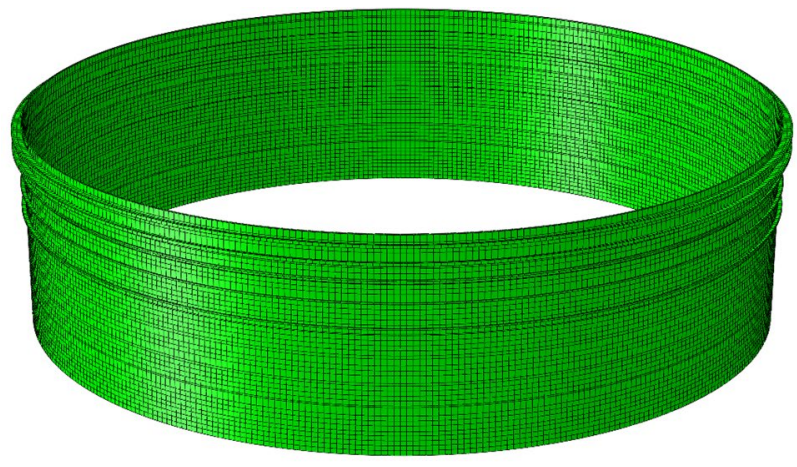

(a) Tank 1

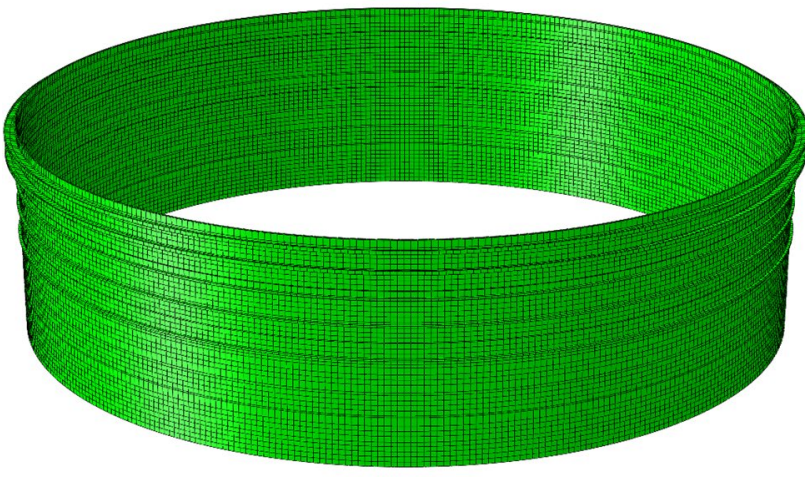

(b) Tank 2

Fig. 2 Tanks finite element analysis model

$30^{\circ}$, the maximum negative pressure is obtained about $80^{\circ}$ and then becomes stable at $135^{\circ}-180^{\circ}$.

It should be noted the coefficients only apply to the fixed top storage tank. For tanks with open-top, an extra uniform negative wind pressure coefficient must be subtracted to take account of the internal suction pressure [20]:

$C_{p}=\left\{\begin{array}{l}-0.8 H / D \geq 2 \\ -0.5 H / D \leq 1\end{array}\right.$

In this paper, the pressure distribution is from Rish [18]. Figure 4 has shown the circumferential distribution of wind pressure coefficient considering internal suction.

\section{Linear buckling analysis}

The linear buckling analysis is based on the linear elastic theory of small displacement and small strain. In other words, the equilibrium equation always established in the initial configuration of the structure at all stages of external force. When the load reaches a certain critical value, the configuration of the structure will suddenly jump to another subsequent equilibrium state, which is called buckling. It is called pre-buckling before the critical point and post-buckling after critical point [21, 22].

Linear buckling analysis that ignores geometric changes and material degradation will provide a preliminary assessment of buckling behavior, get a critical buckling load of the tank. In this paper, the buckling of the tank under wind load and uniform pressure has been analyzed.

\subsection{Linear buckling analysis of storage tanks under uniform pressure}

In the early study of tanks' stability, because of the lack of clear wind load distribution, the uniform external pressure was usually used instead of the wind load for roughly calculated the critical buckling load. Therefore, after making clear the distribution of the wind load on the tank, compare the buckling behavior of the tank under the wind load and the uniform external pressure is also significant.

\subsubsection{Theoretical calculation of tanks under uniform pressure}

For the calculation of critical pressure of tanks under uniform external pressure, storage tanks usually have calculated according to the standard regulations of the various countries on the construction states. One of the formulas calculate the critical pressure of the tank under uniform external pressure is according to the GB50341-2014 Standard [23]:

$\mathrm{P}_{\mathrm{UT1}}=16000 \frac{\mathrm{t}_{\mathrm{min}}^{2.5}}{\mathrm{D}^{1.5} \mathrm{H}}$

Second, according to the theory and numerical calculation method of Donnell, the critical buckling pressure of
Table 3 Fourier coefficients obtained from different sources

\begin{tabular}{lllllllll}
\hline & $\mathrm{a}_{0}$ & $\mathrm{a}_{1}$ & $\mathrm{a}_{2}$ & $\mathrm{a}_{3}$ & $\mathrm{a}_{4}$ & $\mathrm{a}_{5}$ & $\mathrm{a}_{6}$ & $\mathrm{a}_{7}$ \\
\hline Greiner and Derler [29] & -0.65 & 0.37 & 0.84 & 0.54 & -0.03 & -0.07 & & \\
Rish [18] & -0.387 & 0.388 & 0.533 & 0.471 & 0.166 & -0.066 & -0.055 & \\
ACl334 [19] & -0.264 & 0.342 & 0.542 & 0.387 & 0.053 & -0.077 & -0.004 & 0.0341 \\
Pircher et al. [20] & -0.5 & 0.4 & 0.8 & 0.3 & -0.1 & 0.05 & & \\
Macdonald et al. [30] & -0.55 & 0.25 & 0.75 & 0.4 & 0 & -0.05 & & \\
\hline
\end{tabular}




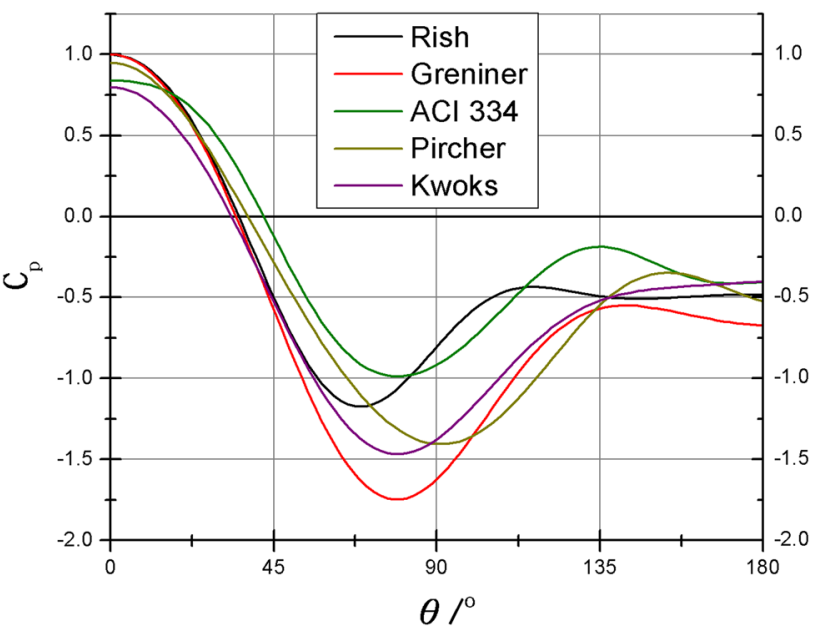

Fig. 3 Distribution forms of Wind load corresponding to different wind pressure coefficients

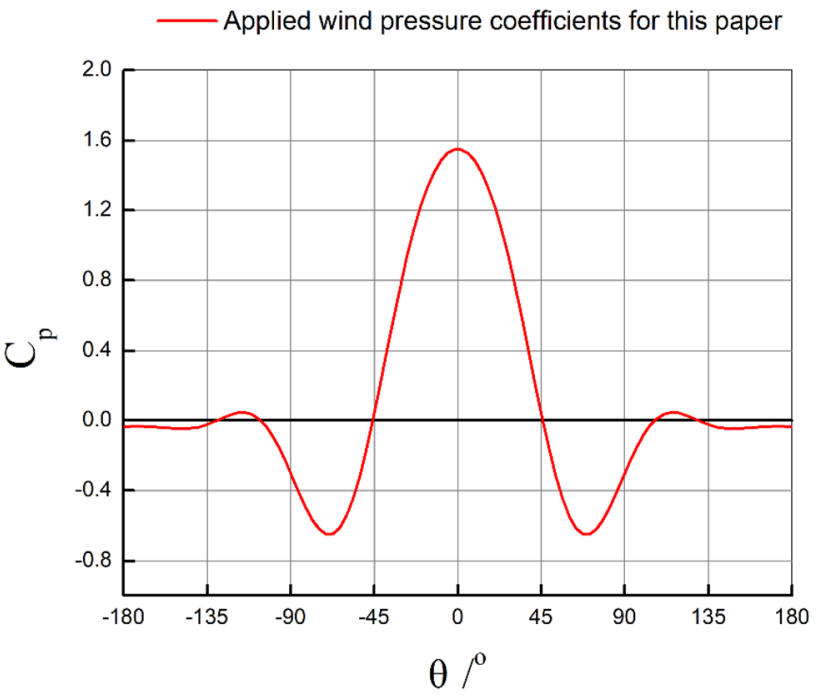

Fig. 4 Applied wind pressure coefficients for this paper

storage tank under uniform external pressure can be calculated by the following formula [24]:

$\mathrm{P}_{\mathrm{UT2}}=\frac{2.59 \mathrm{Et}^{2}}{\mathrm{HD} \sqrt{\mathrm{D} / \mathrm{t}}}$

Also, according to the calculation method of external pressure stability of short cylinders in GB150-2011, the critical pressure of storage tank under external uniform pressure can be calculated [25]:

$P_{\mathrm{UT3}}=\frac{2.6 \mathrm{E}(\mathrm{D} / \mathrm{t})^{-2.5}}{(\mathrm{H} / \mathrm{D})-0.45(\mathrm{H} / \mathrm{t})^{-0.5}}$ where $E$ is the elastic modulus and $t$ is the uniform thickness of the cylinder. For stepped shells, the equivalent height of the cylinder $H$ and equivalent thickness $t$ can be calculated by the following equations [24]:

$H=\sum h_{i} \sqrt{\left(\frac{t_{\text {min }}}{t_{i}}\right)^{5}}$

$\mathrm{t}=\mathrm{t}_{\min }$

where $h_{i}, t_{i}$ is the height and thickness of shell course, respectively, and $t_{\min }$ is the thickness of the thinnest shell course.

The critical uniform external pressure of buckling calculated by theory formulas for different tanks are summarized in Table 4.

\subsubsection{Comparison of linear buckling analysis results and theoretical calculation results of storage tanks under uniform external pressure}

The storage tank model of Tank1, Tank2 without strengthening devices was established in the finite element software Abaqus. Figure 5 shows the buckling modes of tanks without strengthening devices under uniform pressure.

Table 5 listed the buckling loads $P_{U L}$ obtained by the linear buckling analysis of the storage tank under the uniform external pressure and the error of the calculation results by theoretical formulas respectively. It can be seen that in the calculation of critical pressure of tanks, the GB50341 $\left(P_{\text {UT1 }}\right)$ method and the method based on Donnell $\left(P_{U T 2}\right)$ more conservative with an error of about $5 \%$ and $12 \%$, the calculation method of GB150 $\left(P_{\text {UT3 }}\right)$ more radical with about $1 \%$ of the error.

Besides, Table 6 compares the results of critical pressure $P^{\prime}{ }_{U L}$ calculation with the linear buckling analysis of tanks with reinforcement devices, listed the calculation and the error of calculation results by theoretical formulas.

In the course of calculating the tank with reinforcement devices, due to the equivalent height conversion of the unreinforced tank wall, there was a big error between the calculation result and the simulation result. The results showed the GB50341 ( $\left.P_{\text {UT1 }}^{\prime}\right)$ method and the method

Table 4 Theoretical calculation of critical pressure for tanks without strengthening devices

\begin{tabular}{lll}
\hline$P_{U T}(\mathrm{~Pa})$ & Tank1 & Tank2 \\
\hline$P_{U T 1}($ Donnell) & 929.78 & 914.37 \\
$P_{U T 2}(\mathrm{~GB} 50341)$ & 864.93 & 855.91 \\
$P_{U T 3}(\mathrm{~GB} 150-2011)$ & 970.00 & 955.9 \\
\hline
\end{tabular}


Fig. 5 The buckling modes of tanks without strengthening devices under uniform external load
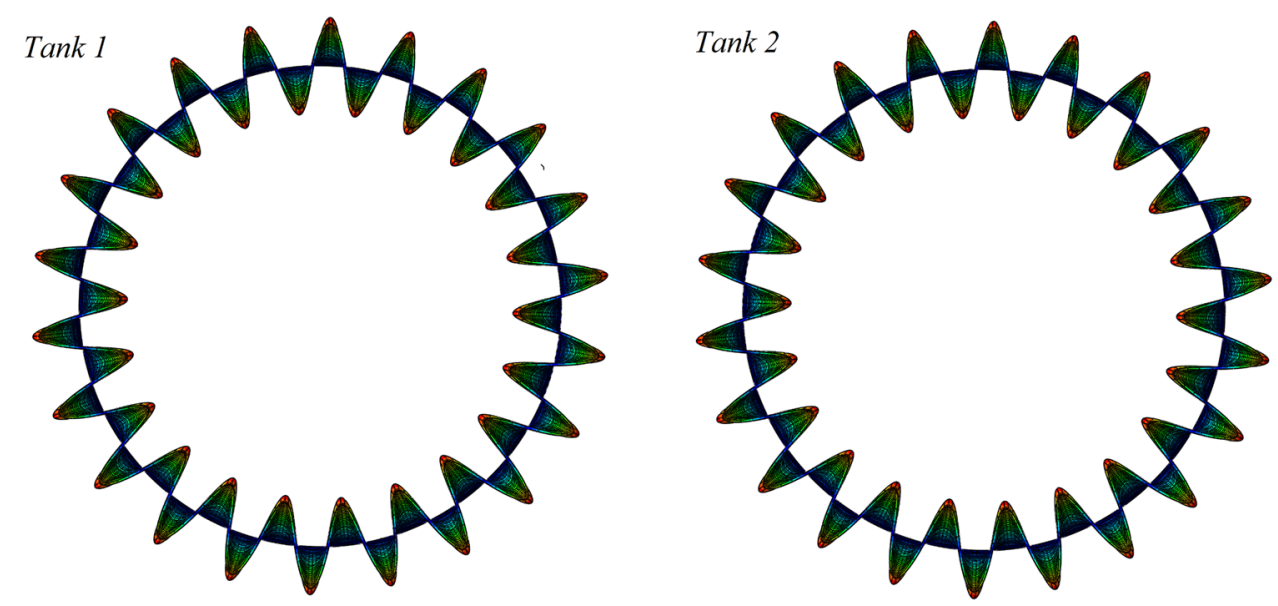

Table 5 Comparison of linear buckling analysis results and theoretical calculation results of storage tanks under uniform external pressure

\begin{tabular}{lrr}
\hline & Tank1 & \multicolumn{1}{c}{ Tank2 } \\
\hline$P_{U L}(\mathrm{~Pa})$ & 969.63 & 963.41 \\
$P_{U L} / P_{U T 1}$ & 1.04 & 1.05 \\
$P_{U L} / P_{U T 2}$ & 1.12 & 1.12 \\
$P_{U L} / P_{U T 3}$ & 0.99 & 1.01 \\
\hline
\end{tabular}

Table 6 Theoretical calculation of critical pressure for tanks with strengthening devices

\begin{tabular}{lcc}
\hline$P(\mathrm{~Pa})$ & Tank1 & Tank2 \\
\hline$P^{\prime}{ }_{\text {UL }}$ & 4987.7 & 7244.1 \\
$P^{\prime}{ }_{\text {UT1 }}$ (Donnell) & 3706.4 & 5821.2 \\
$P^{\prime}{ }_{\text {UT2 }}$ (GB50341) & 3469.4 & 5449.1 \\
$P^{\prime}{ }_{\text {UT3 }}$ (GB150-2011) & 4338.9 & 7494.2 \\
$P_{\text {UL }}^{\prime} / P_{\text {UT1 }}$ & 1.34 & 1.24 \\
$P^{\prime}{ }_{\text {UL }} / P_{\text {UT2 }}$ & 1.43 & 1.32 \\
$P^{\prime}{ }_{U L} / P_{\text {UT3 }}$ & 1.15 & 0.96 \\
\hline
\end{tabular}

based on Donnell $\left(P^{\prime}{ }_{\text {UT2 }}\right)$ more conservative, with a calculation error of $29 \%$ and $37 \%$, the calculation method of GB150 ( $\left.P_{\text {UT3 }}^{\prime}\right)$ more radical with about $9 \%$ of the error.

\subsection{Linear buckling analysis of storage tanks under wind pressure}

The first and second critical buckling load $P_{W L 1,2}$ and $P^{\prime}{ }_{W L 1,2}$ gained from linear buckling analyses for tanks under the wind load is listed in Table 7. It can be found in the first critical load equal to the second critical load for each tank. And the buckling load of the tank under wind load about $35 \%$ lower than that under uniform external pressure. The critical pressure of the two tanks under the wind load $\left(P_{W L 1,2}\right)$ is $666.11 \mathrm{~Pa}$ and $675.72 \mathrm{~Pa}$. Figures 6 and 7 shows
Table 7 Comparison of linear uniform external pressure and under wind pressure buckling analysis results under

\begin{tabular}{lcc}
\hline$P(\mathrm{~Pa})$ & Tank1 & Tank2 \\
\hline$P_{W L 1}$ & 666.11 & 675.72 \\
$P_{W L 2}$ & 666.11 & 675.72 \\
$P_{W L 1}^{\prime}$ & 3297.6 & 5197.0 \\
$P_{W L 2}^{\prime}$ & 3297.6 & 5197.0 \\
$P_{W L 1,2}^{\prime} / P_{W L 1,2}$ & 4.95 & 7.69 \\
\hline
\end{tabular}

the buckling modes of those two tanks under the wind load.

According to Table 7. It can be found, after the installation of reinforcement devices, the critical pressure of the tank greatly increased. Tank 1 increased by $495 \%$, Tank 2 increased by $769 \%$.

Obviously, Tank2 gained a more strengthening effect than Tank1, about 274\%. The increasing effect of the critical pressure of these two tanks is different because of the different installation positions of strengthening devices. The installation positions of reinforcing rings of Tank2 more closing to the bottom of the tank.

\section{Geometrically nonlinear analyses}

The geometrically nonlinear buckling analysis needs to test repeatedly to gain accurate critical loads, and its calculation accuracy is related to the size of the applied load. And the accuracy of results can only be guaranteed if the applied load is slightly greater than the critical load. Therefore, the nonlinear buckling analysis of the storage tank has carried out in this paper to track the whole process of tank buckling.

This section has considered the geometrically nonlinear buckling behavior of the tank. And in order to gain the result of geometric nonlinear buckling analysis, all geometric nonlinear buckling analyses in this paper use very

\section{SN Applied Sciences}


Fig. 6 Vertical buckling modes for different tanks under the wind load (first modes)

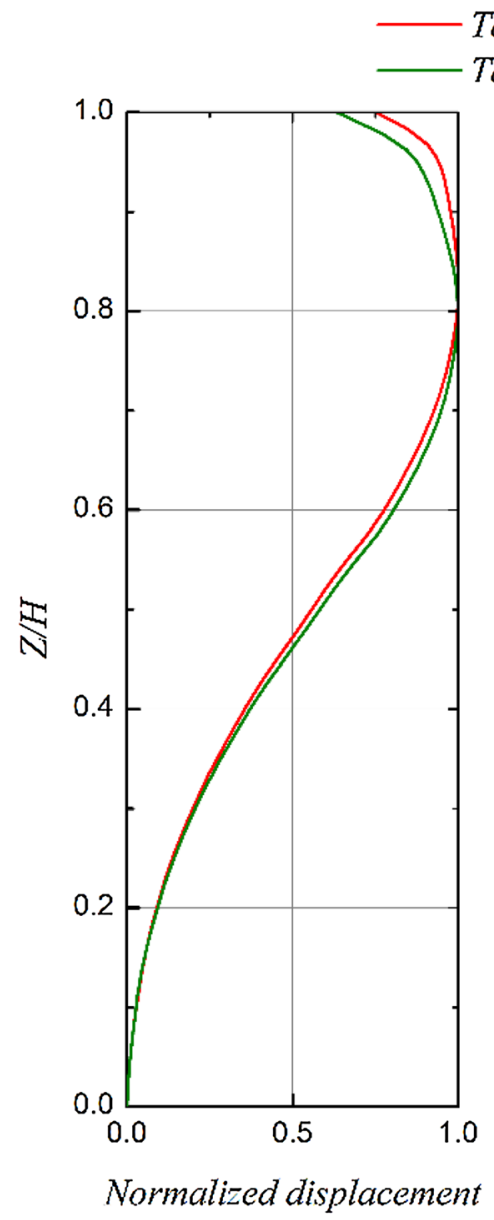

(a) Without reinforcement devices

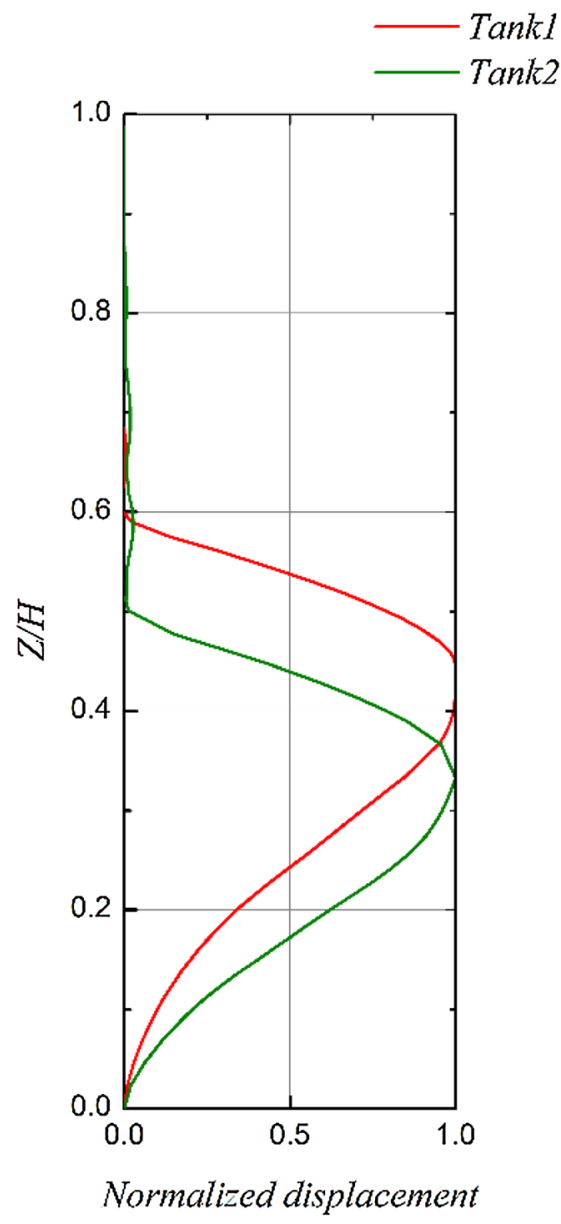

(b) With reinforcement devices small same classical buckling mode imperfections as initial imperfections to facilitate the convergence of the calculation (the amplitude of the imperfections used is 0.01 times the thinnest wall thickness of the tank). Figure 8 plotted the load-displacement curves of tanks, in which the symbol $\Delta$ means radical displacement with inward positive. It can be found the buckling behavior of storage tanks is typically branch instability. And in the pre-buckling stage, the load-displacement curve is close to linear.

As shown in Table 8, the critical buckling load of geometrically nonlinear analysis $\left(P_{W G}\right.$ and $\left.P^{\prime}{ }_{W G}\right)$ under wind load is close to the result of linear buckling analysis $\left(P_{W L 1,2}\right.$ and $\left.P^{\prime}{ }_{W L 1,2}\right)$. Figure 9 is the buckling deformation of the tank under the critical buckling load gained from the geometrically nonlinear buckling analysis. It can be found that these deformations are similar to the first-order waveforms of the eigenvalue analysis results of linear buckling analysis.

Through comparing the results of geometrically nonlinear analysis and linear buckling analysis. It can be believed the linear elastic bifurcation analysis is a good signal for the buckling load and rough deformation at the maximum load point although it cannot predict the deformation exactly.

\section{Influence of various factors on the stability of storage tanks under external pressure}

In fact, for in-service tanks, there are many factors influenced the stability of tanks under external pressure. Such as the influence of the installation of strengthening devices, the influence of liquid stored in the tank and the common action of these two is discussed in this paper.

\subsection{Influence of Tank's strengthening device}

For the in-service tank, wind girders and reinforcement rings are generally arranged as reinforcement devices to keep their roundness when they are affected by wind load [26]. Although the size parameters and the installation position of reinforcement devices will be designed by using the national standards at the design stage. In fact, 
Fig. 7 Circumferential buckling first and second modes for different tanks without installed reinforcement devices under the wind load

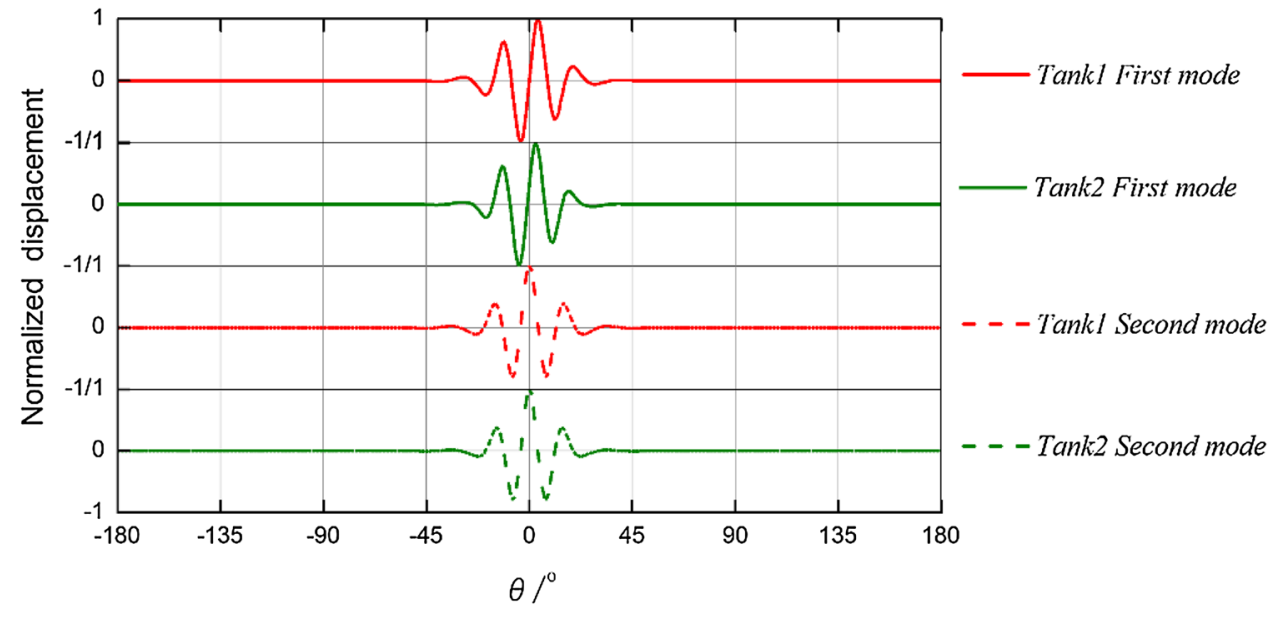

(a) Without reinforcement devices

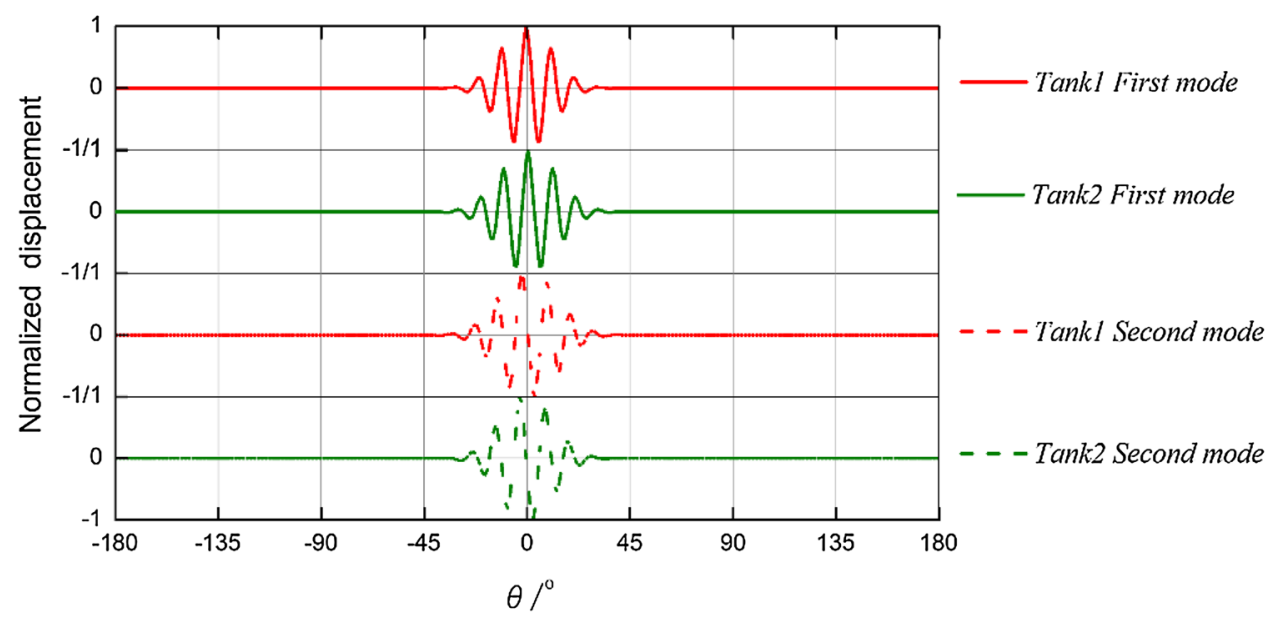

(b) With reinforcement devices

Table 8 Comparison of geometric nonlinear analysis results with linear buckling analysis results

\begin{tabular}{lrr}
\hline$P(\mathrm{~Pa})$ & \multicolumn{1}{c}{ Tank1 } & \multicolumn{1}{c}{ Tank2 } \\
\hline$P_{W G}$ & 627.71 & 641.54 \\
$P_{W G}^{\prime}$ & 3445.49 & 5177.57 \\
$P_{W G}^{\prime} / P_{W G}$ & 5.490 & 8.071 \\
$P_{W G} / P_{W L 1,2}$ & 0.942 & 0.949 \\
$P_{W G}^{\prime} / P_{W L 1,2}^{\prime}$ & 1.045 & 0.996 \\
\hline
\end{tabular}

the installation position of the wind girder of the two inservice tanks always different. In this article, the installation position of reinforcement devices for two tanks shown in the following Table 9.

Review Fig. 6 and Table 8. It is obvious that the strengthening effect of Tank2 slightly better than that of Tank1. The reasons may because the installation position of strengthening devices of Tank 2 is more dispersed and the position of the last reinforcement ring is closer to the bottom tank wall. Figure 6 shows that the deformation of the
Fig. 8 Geometrically nonlinear equilibrium paths of tanks under the wind load

\section{SN Applied Sciences}


Fig. 9 The buckling deformation of tanks gained from the geometrically nonlinear buckling analysis

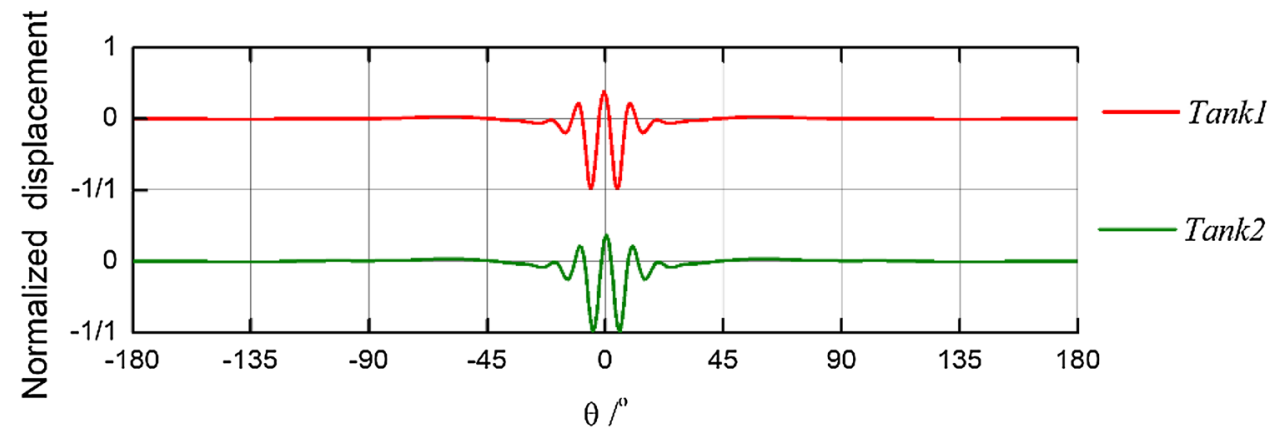

Table 9 Height of installation position of strengthening devices such as wind girders of two storage tanks (distance from tank bottom)

\begin{tabular}{lll}
\hline Mounting height $(\mathrm{m})$ & Tank1 $(\mathrm{m})$ & Tank2 $(\mathrm{m})$ \\
\hline 1st Girder & 20.8 & 20.8 \\
2nd Girder & 19.1 & 18.9 \\
1st Ring & 17.4 & 16.34 \\
2nd Girder & 15.2 & 13.78 \\
3rd ring & 12.7 & 10.57 \\
\hline
\end{tabular}

shell above the wind girder is reduced considerably, and for Tank 1 and Tank2, the displacement of the shell above the height of reinforcing rings installed is almost zero. And the location of the maximum buckling deformation of tanks with the installation of reinforcement devices obviously moved down. This means the reinforcement device significantly strengthens the stiffness of the upper part of the shell and improves the anti-wind buckling capacity of the shell.

\subsection{Influence of stored liquid}

The liquid stored in the tank produces two effects: (1) the internal suction caused by the wind disappears under the liquid level, (2) the static water pressure will be applied to the inner wall of the tank to offset the windward positive pressure $[27,28]$. So the storage of liquid can improve the stability of storage tanks under wind load.

In order to understand the influence mode of liquid stored in the tank, several different liquid levels were used for analysis. The density of stored liquid reference engineering actual storage of liquid density $\left(840 \mathrm{~kg} / \mathrm{m}^{3}\right)$. And for tracking the change between buckling loads and the hydrostatic pressure more accurately, the loading sub-step of the hydrostatic pressure is $10 \%$ of the full-load stage.

Figure 10 shows the vertical buckling modes of the maximum displacement at different liquid levels in each tank. It can be seen that the effect of the stored liquid on the different tanks is similar. And with the increase of liquid

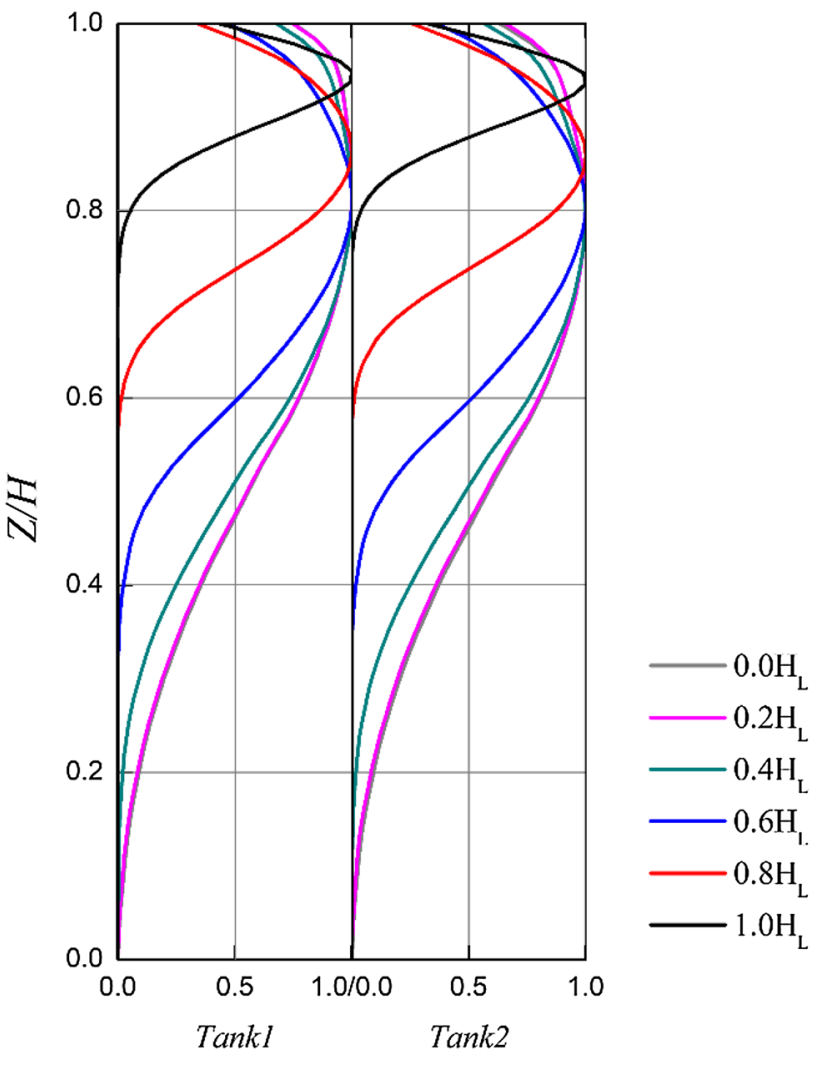

Fig. 10 The vertical buckling modes of tanks at different liquid level

level, the bottom buckling deformation of the tank is significantly reduced and the maximum displacement is constantly moving up. This is the opposite of the effect of reinforcement devices on the buckling behavior of the tank, which indicated the stored liquid significantly enhances the tank by strengthening the stiffness of the bottom of the tank, thus improving the stability of the shell under strong wind load.

And the normalized buckling loads with various liquid levels are summarized in Fig. 11. Due to the linear buckling analysis and geometrically nonlinear buckling results are near, only the linear buckling analysis results are given for discussion. 


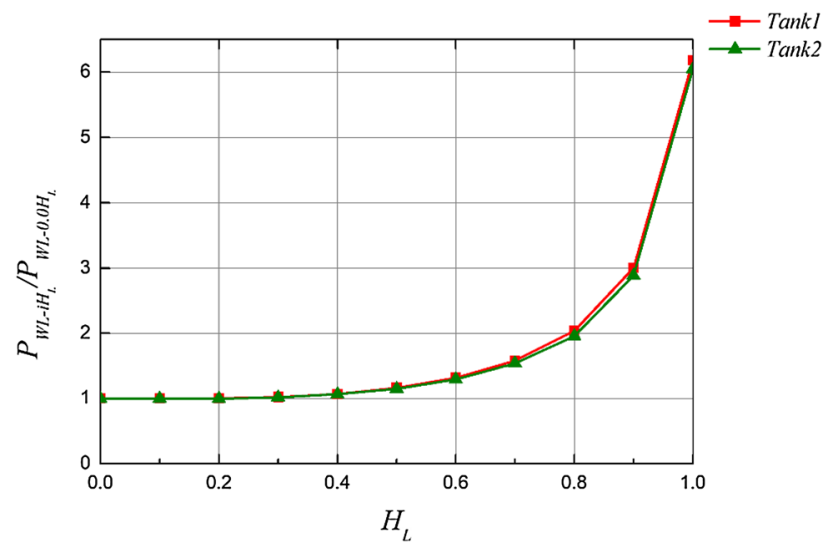

Fig. 11 Liquid level-load variation curve based on empty state

According to the results of analyses. It can be found that for the lower water level, $0.1 H_{L} \sim 0.4 H_{L}$, almost not improve the anti-buckling ability of those two tanks. After the middle water level $\left(0.6 \mathrm{H}_{L}\right)$, the wind buckling load of tanks generally begins increasing, and when the liquid level is close to a full tank, the wind buckling load of tanks increases greatly. It proves that it is effective to impound sufficient water for empty tanks before a hurricane to prevent tanks from buckling due to strong wind load.

\subsection{Composite effect of the strengthening device installation position and liquid level on external pressure stability of storage tank}

In fact, for in-service tanks, the strengthening of the tank is on reinforcement devices and stored liquid common effect. Figure 12 shows the vertical buckling mode of Tank1 and Tank2 (with reinforcement devices) under different liquid levels. For Tank2, it can be seen that with the increase of the liquid level, the maximum displacement of the tank is increasing. And there is a significant change in the buckling mode when the fluid level arrivals the installation position of the reinforcement device (at $0.6 \mathrm{H}_{L}$ and $0.8 H_{L}$ ). Figure 13 summarizes the normalized variation of the buckling load for linear buckling analysis of tanks with stiffeners based on empty states as the liquid level increases.

Besides, Fig. 14 shows the nonlinear equilibrium path under several liquid levels of Tank1 and Tank2 containing reinforcement devices based on the analysis results of empty tanks. According to the results of the linear buckling analysis and the geometrically nonlinear buckling analysis of the tank with the change of liquid level under the action of wind load. It can be seen that as follows:

(1) The existence of the strengthening devices has greatly improved the external pressure stability of

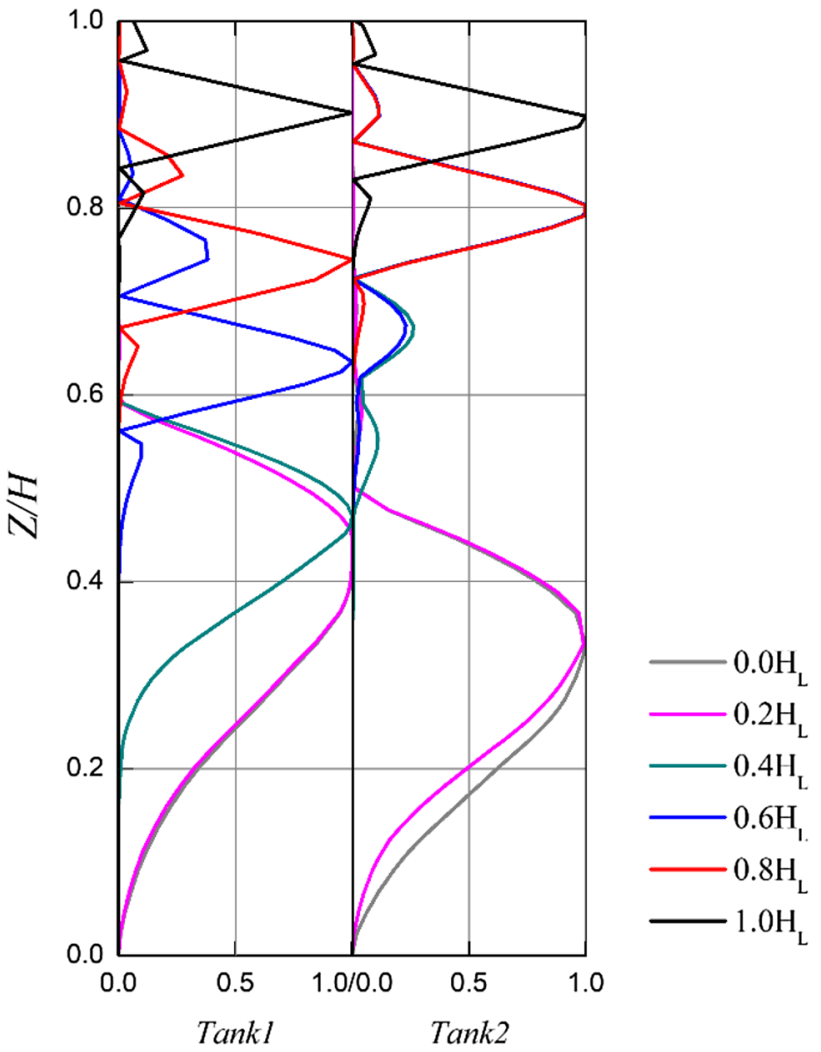

Normalized displacement

Fig. 12 The vertical buckling mode of tanks (with reinforcement devices) under different liquid levels

tanks. For Tank1 and Tank2 without strengthening devices, if they want to achieve the same enhance effect need to loading at least $90 \%$ of the stored liquid of those tanks.

(2) The enhancement mechanism of the strengthening device and the stored liquid on the stability of the storage tank under external loads are different. And make the effect of the liquid stored in the tank containing the strengthening device on the external pressure stability of the tank is partially offset, especially for Tank2.

(3) The weakening degree of the effect of different installation positions on the stability of the tank under external pressure caused by the stored liquid is different. If manufacturers want to enhance the stability of the tank under external pressure contained strengthening devices by storing liquid. It is necessary to analyze the installation position of the strengthening device for the specific storage tank. 

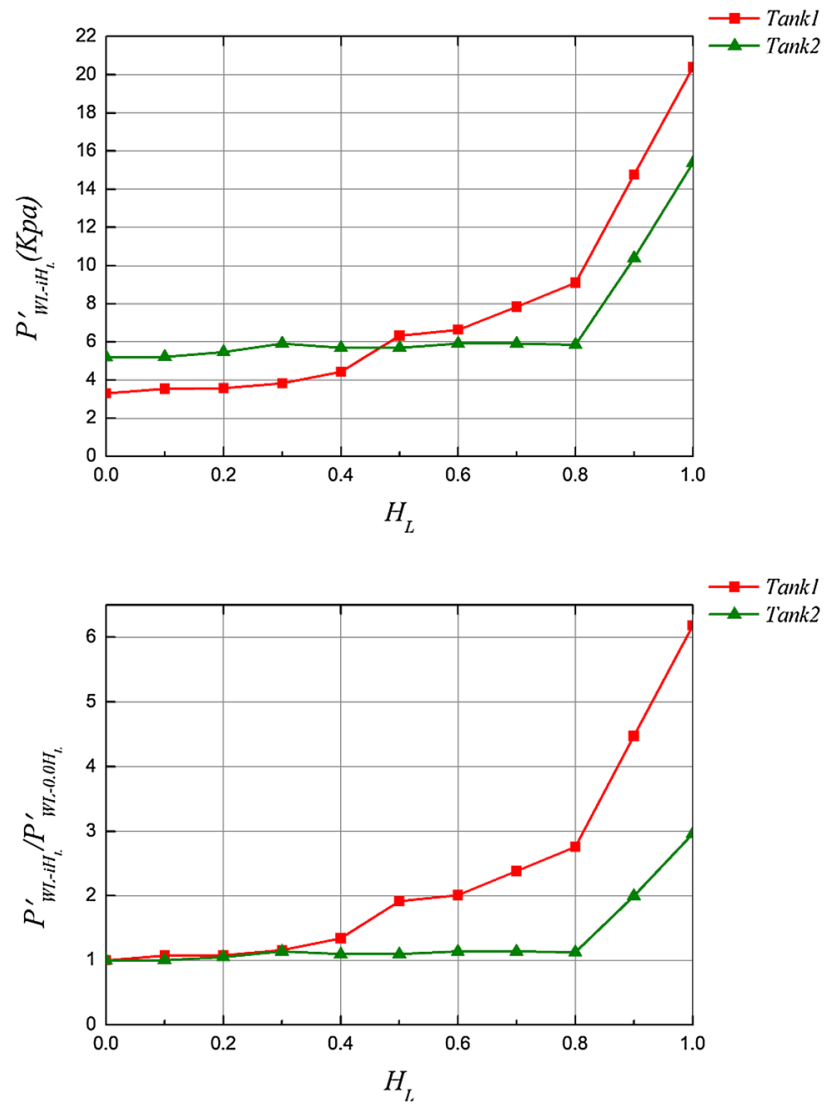

Fig. 13 Liquid level-load curve for tanks with reinforcement devices

\section{Conclusion}

In this paper, a large number of numerical simulations have been conducted to study the effects of various factors on the stability of those two in-service tanks. The main conclusions of this paper can be summarized as follows:

(1) Among the comparison of formulas for calculating critical buckling pressure of storage tanks under uniform pressure. The theoretical calculation method based on Donnell is closer than the GB50341 method to the results of finite element analysis, and the results are slightly conservative. And the formula for calculating the critical pressure of the short cylinder in GB150 is also applicable to the equivalent tank model, which only has a small error compared with the finite element results.

(2) The stability of tanks under external pressure will be greatly affected by the different installation positions of the tank strengthening device. Taking those two in-service tanks studied in this paper as an example, the critical buckling load difference between those two tanks under the condition of no liquid stored is nearly $40 \%$. (a) Tankl

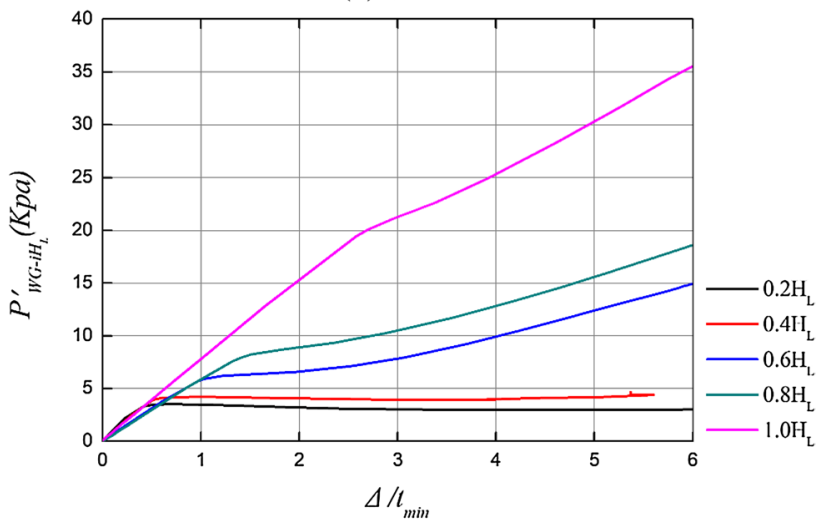

(b) Tank2

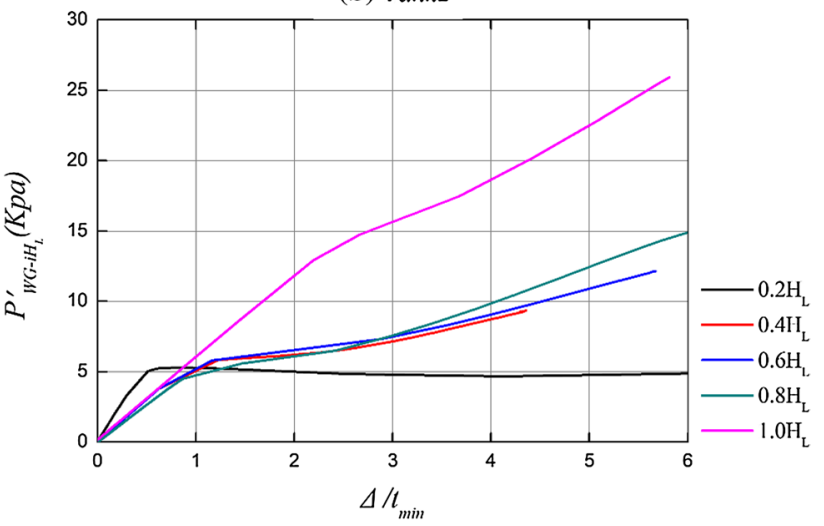

Fig. 14 Nonlinear equilibrium path of Tank1 and Tank2 (with reinforcement devices) at several liquid levels

(3) When under the wind load, the effect of the stored liquid to the stability of similar tanks is consistent.

(4) The stored liquid enhances the anti-buckling ability of in-services tanks under wind loads by enhancing the rigidity of the bottom of the tank. While the reinforcement device enhances the ability by strengthening the rigidity of the top of the tank.

(5) The installation of the reinforcement device can effectively improve the wind buckling ability of the storage tank. And for in-services tanks which containing reinforcement devices, the stored liquid also can make positively interact with the reinforcement device to affect the stability under external loads.

Acknowledgements This work was supported by the Fundamental Research Funds for the Central Universities of China (Grant No. PA2019GDPK0054).

\section{Compliance with ethical standards}

Conflict of interest On behalf of all authors, the corresponding author states that there is no conflict of interest. 


\section{References}

1. Global Energy Statistical Yearbook (2018) 2018 Global Energy Statistical Yearbook Total Energy, Consumption

2. CEMLDSP (2011) 2011 China's energy medium and long-term development strategy project research group (CEMLDSP) China's Energy Medium and Long-Term $(2030,2050)$ Development Strategy Research: Electric Power, Oil and Gas, Nuclear Energy, the Environment Volume Science Press, Beijing

3. BS EN 14015-2004, Specification for the design and manufacture of site built, vertical, cylindrical, flat-bottomed, above ground, welded, steel tanks for the storage of liquids at ambient temperature and above, British Standard 14015-2004

4. Godoy LA (2007) Performance of storage tanks in oil facilities following Hurricanes Katrina and Rita. J Perform Constr Facil ASCE 21(6):441-449

5. Flores FG, Godoy LA (1998) Buckling of short tanks due to hurricanes. Eng Struct 20(8):752-760

6. Jaca RC, Godoy LA (2010) Wind buckling of metal tanks during their construction. Thin Walled Struct 48:453-459

7. Godoy LA (2016) Buckling of vertical oil storage steel tanks: review of static buckling studies. Thin Walled Struct 103:1-21

8. Portela G, Godoy LA (2005) Wind pressures and buckling of cylindrical steel tanks with a dome roof. J Constr Steel Res 61:808-824

9. Portela G, Godoy LA (2005) Wind pressures and buckling of cylindrical steel tanks with a conical roof. J Constr Steel Res 61:786-807

10. Zhao Y, Cao QS, Su L (2013) Buckling design of large circular steel silos subject to wind pressure. Thin Walled Struct 73:337-349

11. Zhao Y, Lin Y (2014) Buckling of cylindrical open-topped steel tanks under wind load. Thin Walled Struct 79:83-94

12. Maraveas C, Balokas GA, Tsavdaridis KD (2015) Numerical evaluation on shell buckling of empty thin-walled steel tanks under wind load according to current American and European design codes. Thin Walled Struct 95:152-160

13. Shokrzadeh AR, Sohrabi MR (2016) Buckling of ground-based steel tanks subjected to wind and vacuum pressures considering uniform internal and external corrosion. Thin Walled Struct 108:333-350

14. Uematsu Y, Yamaguchi T, Yasunaga J (2018) Effects of wind girders on the buckling of open-topped storage tanks under I quasistatic wind loading. Thin Walled Struct 124:1-12
15. Uematsu Y, Koo C, Yasunaga J (2014) Design wind force coefficients for open-topped oil storage tanks focusing on the windinduced buckling. J Wind Eng Ind Aerodyn 130:16-29

16. Eurocode 3 (2007) Design of steel structures-Part 1-6, strength and stability of shell structures. European Standard EN 1993-1-6

17. Eurocode 1 (2005) Actions on structures-Part 1-4: general actions-wind actions. European Standard EN 1991-1-4

18. Rish RF (1967) Forces in cylindrical chimneys due to wind. Proc Inst Civ Eng ASCE 36:791-803

19. ACI-ASCE Committee 334 (1991) Reinforced concrete cooling tower shells-practice and commentary. $\mathrm{ACl} 334-2 \mathrm{R}$

20. Pircher M, Bridge RQ, Greiner R (2002) Case study of a mediumlength silo under wind loading. Adv Steel Struct 2:667-674

21. Pavlovic P, Folic R, Radonjanim V, Tatomirovic M (1997) The testing and repair of steel silo. Constr Build Mater 11(5):353-363

22. Wang $Z$ (2013) Wind-induced buckling analysis of large oil storage tanks. Zhejiang University

23. GB50341-2014. Code for design of vertical cylindrical welded steel oil tanks. China Standard 50341-2014

24. BS2654-1989. Specification for manufacture of vertical steel welded storage tanks with butt-welded shells for the petroleum industry. British Standard 2654-1989

25. GB150-2011. Pressure vessels. China Standard 150-2011

26. API 650 (2012) Welded tanks for oil storage. American Petroleum Institute

27. Chiang YC, Guzey S (2019) Influence of internal inward pressure on stability of open-top aboveground steel tanks subjected to wind loading. J Press Vessel Technol Trans ASME 141:15

28. Portela G (2004) Wind pressure and buckling of metal cantilever tanks. PhD thesis, University of Puerto Rico, Mayagüez Campus, Puerto Rico

29. Greiner R, Derler P (1995) Effect of imperfections on windloaded cylindrical shells. Thin Walled Struct 23:271-281

30. Macdonald PA, Kwok KCS, Holmes JD (1988) Wind loads on circular storage bins, silos and tanks: I. Point pressure measurements on isolated structures. J Wind Eng Ind Aerodyn 31(2):165-187

Publisher's Note Springer Nature remains neutral with regard to jurisdictional claims in published maps and institutional affiliations. 